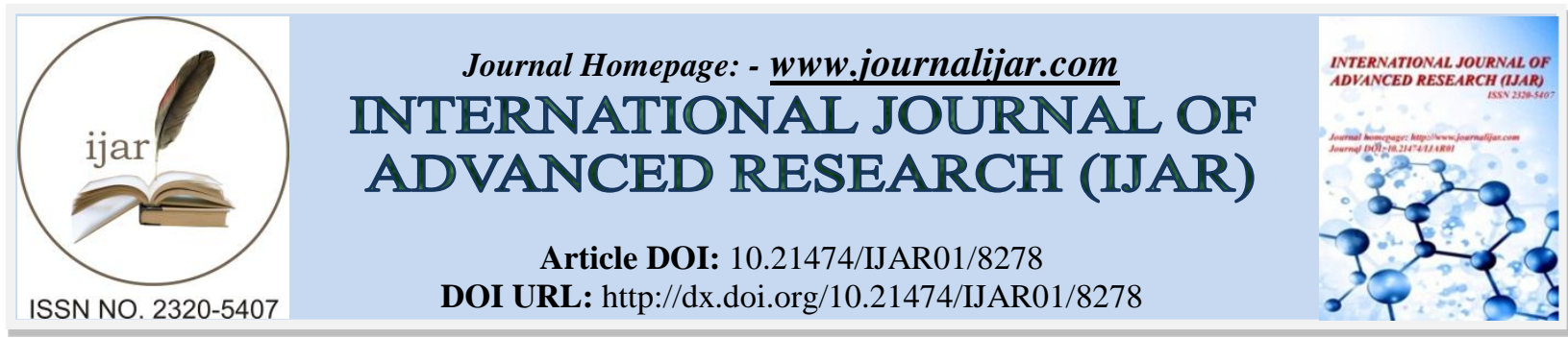

RESEARCH ARTICLE

\title{
PUBLIC ASSET MANAGEMENT: THE REALIZATION OF LOCAL WISDOM THROUGH EMILE DURKHEIM'S IDEA OF SOCIAL SOLIDARITY.
}

\author{
Sulthan Alaudin, Syarifuddin and Darwis Said.
}

Hasanuddin University.

\section{Manuscript Info}

\section{Manuscript History}

Received: 20 October 2018

Final Accepted: 22 November 2018

Published: December 2018

Keywords:

Asset management, Assitinaja, Social Solidarity.

\section{Abstract}

This study aims to examine the concept of assitinaja in Bombana Regency's asset management information system, by looking at how actors who act adapt to the organizational environment and leadership style, as well as interactions between actors. This research was conducted at the Regional Financial and Asset Management Agency (BPKAD) of Bombana Regency . This study uses Emile Durkheim's analysis of Social Solidarity. This study investigates the accounting information system model that supports decision making, especially decisions related to fixed assets. In the final part of this study, critics of the characteristics needed in compiling an accounting information system are reliable will appear. The results of this study highlight the benefits of Durkheim's method adopted in this study, namely mechanistic social solidarity. This is nothing new, but it is a further development. The concept of government organizations is primarily useful for describing the phenomenon as a whole (in terms of asset management) By looking at Bombana Regency we have gotten a spectacle of how previously the voices were inaudible, increasing recognition at the national level through the BPK Audit. Despite the fact that managers in work units (dinas) are not part of certain categories of professionals, such as accountants, their situation has created work groupings, but synergized in social solidarity. This grouping can be relevant even though they are not based on a particular career background or identity. Furthermore, as suggested by Durkheim, they came from outside the traditional site (mechanistic), that it originated from a common interest which led to recognition on social networks.

Copy Right, IJAR, 2018,. All rights reserved.

\section{Introduction:-}

The features of management information and policies, as well as the control of the policies that accounting information systems have, have two main functions, according to Zimmerman (1997): support the decision-making process and improve management control in the organization (eg, performance and cost awareness). The first function refers to the ability of information to promote rationality at all stages of the decision-making process (from problem identification to the implementation of solutions). In this case, for example, asset accounting information systems are expected to be closely related to the quality of decisions, both strategic and operational decisions.

Corresponding Author:-Sulthan Alaudin.

Address:-Hasanuddin University. 
Anderson and Young (1999) provide evidence that the successful implementation of information is positive related to the relevance of managerial decisions.

The second function refers to activities that control the organization or performance of units and the behavior of employees. In this case, accounting information systems provide information on past actions and outcomes, which must then be linked to a kind of culture and leadership style that motivates and harmonizes organizational behavior in the creation of accounting information, such as assets. In addition, accounting systems in public organizations can provide information to the various Interest Groups Accountability In this case, how public assets are used.

It also shows the relationship between information and culture and management style a close relationship with accounting information systems and the performance of public managers. If the information related to the unit of performance is appropriate, then the policies and controls based on that information will logically be better (Milgrom and Roberts, 1992). Conversely, the inability of accounting information systems to provide high-quality information (valid, trustworthy, timely and inexpensive) provide, Affect the lack of useful Information for managers in policy-making, control and implementation of accountability. Meanwhile, Anthony (1965) emphasizes the importance of booking system information system design features when used by an organization.

It is known that managers use information to manage their units if they believe that the information is accurate, relevant, timely, and cost-effective. In this context came Nicolaou (2000) concluded that the accuracy and effectiveness of the information to facilitate and control accounting information was found to be satisfactory. This shows that the design of Accounting information systems must be based on the needs of the manager, which means that the duration and relevance of the accounting information must be available when the information is needed, and the format of the system and the procedures for the information must be appropriate.

The task of regulating and maintaining a list of government assets has been entrusted to the Regional Agency for Finance and Asset Management (BPKAD), which is the legal successor to the regional government. BPKAD pursues a strategy for managing regional government assets. This strategy relates to asset management plans. Following this strategy, the Government Ordinance on the Management of State Property / Regional Assets established regional rules for the management of regional assets. This regulation defines and covers all types of local government assets, regional asset management principles, types and forms of share and corporate governance, and the scope of government assets. The scope and administrative power of the management of government assets (funded from the state budget) is the responsibility of BPKAD, which regulates the preparation and management of a list of government assets.

Before this background developed the government of Bombana Regency before 2013 a set of strategic development plans and strategies. Unfortunately, all strategies have been developed without analyzing in detail the valuation or valuation of financial and non-financial assets of government agencies or government entities regions, companies, institutions and other institutions formed by the central or regional government. In this case, it can be said that the information on the accounting of fixed assets in Bombana Regency Not exactly and cannot meet the interests of the public, as many assets are not captured. This causes. that the local government the fixed assets not optimally used for the civil service.

Based on the concept that public authorities must be fully accountable to the community in asset management, and the most authorized are central and regional authorities or existing public entities that both oversee and maintain certain assets. Regarding the government of Bombana Regency this institution has made asset management practices that have priority over financial assets, with some constraints on non-financial assets. For example, they do not know exactly what assets they own, manage or use to carry out their activities. This study therefore discusses the prerequisites required to Bombana Regency initiate appropriate asset management procedures for the public sector especially those who are the authorities can stop the performance of asset usage to measure and integrate into the asset management process to maximize asset productivity.

On this basis and in the analysis of the regulatory framework, the issues related to the management of the State's current assets can be summarized as follows: The information for a list of government assets is still incomplete, while the information for certain assets is excessive, while this is not the case with other assets or is disseminated to different locations or institutions. In general, there is a misunderstanding regarding the definition of state assets and inadequate classification of state assets. Another emerging issue is the existence of licensing procedures relating to 
the ownership, management and use of public sector assets. Secondly, the lack of principles in the assessment of competent assets and personnel. Therefore, several problems occurred when the APBD did not contain all the data of all asset objects (asset types) of Bombana Regency fully combined, this is due to the fact that: (1) Documentation of government assets distributed in various SKPD records who use assets and / or have been designated by the Government to manage, use or release assets; (2) The information on the assets has been disseminated, provided that they are included in the balance sheet, the off-balance sheet reports and the analysis budget were recorded when they are knowledgeable and except for Household funds are users, The aim of this study is the Concept of Assitinaja in the Asset Management Information System from Bombana Regency to investigate by examining how actors who adapt to the organizational environment and leadership style, as well as the interactions between actors, are analyzed through the analysis of social solidarity by Emile Durkheim.

\section{Materials and Methods:- \\ Research design}

This study will be the underlying Explain conflict backward the realization of local wisdom in the Management of public assets in the government of Bombana Regency In this case will the Regional Financial and Asset Management Agency (BPKAD) of Bombana Regency the main informant of this study, as they are responsible for managing the assets of the government Bombana Regency is responsible, Therefore, this study used a qualitative approach the social analysis Method of Emile Durkheim, to interpret the results.

\section{Data collection method}

This study is an evolution of the technocrat approach accounting policies by conducting discussions and identifying cultural accents. In particular, the cultural context (symbol, language, ideology, ritual) examined in detail and myth ) and behavioral concepts with accounting principles, in particular accounting information systems and accounting controls, in order to optimize the accountability of asset management. The Become researchers different methods work together like observation, in detailed interviews (detailed Interview) and text analysis and documentation. The documentation of the observations and interviews is done with a smartphone to record interviews and to photograph the situation around the informants and research sites, and to create interview manuscripts with a laptop device, to store and record research data. The collection of interview data, observations of interactions, documents, data, pictures or photos is done with the knowledge and permission of the informant.

\section{Data analysis techniques}

The study was conducted observing the relationship between organizational units and the relationship of top-level organizational units. In addition, this study also observed the morality and culture of community organizations within the institution in the interaction. The focus of the analysis is on the solidarity associated with the bookkeeping and administration of wealth management in the government.

\section{Results:-}

Exploration of asset management in Bombana Regency provides useful evidence to analyze the implementation of unifying policies in the regions, which are populated by diversity of opinions when operating at several levels of the organization. There is diversity in asset types, stakeholder interests, and functional background of the managers involved.

The implementation of asset management in this diversity is analyzed by drawing concepts from government organizations and paying attention to the various actors involved, both the dominant voice and the "inaudible" voice. The perspective of social solidarity here provides relevance related to the relational and dynamic arrangements of the local government. The cases studied show different levels of controversy and achievement, providing a very diverse picture of effectiveness in asset management policies.

The results of this study highlight the benefits of Durkheim's method adopted in this study, namely mechanistic social solidarity. This is nothing new, but it is a further development. The concept of government organizations is primarily useful for describing the phenomenon as a whole (in terms of asset management) where the actors involved voice their voices in the organization, of course, all voices are not the same, there are some who are dominant while others are marginalized. Further attention is paid to the three basic components of government 
organizations, namely speech, dialogue, and actors, which help in understanding the causes of tension and controversy, which reveals the actor's ability to build a universal language.

This is a case that occurred in Bombana Regency, where social solidarity strengthened, because each functional manager applied the practice of equity to their respective work units, and prioritized the efforts of the leadership to establish a comprehensive policy. The attempt to encourage votes was dominant, by establishing a centralized "orchestra" that had failed in the previous period of leadership, in which the "orchestra" was successfully put together in the current leadership period leading to different discourses from several layers of work units on one another, aimed at to fulfill regional interests and public services to the fullest.

In the previous leadership period, in Bombana Regency there appeared to be greater disharmony over asset management, and in various ways such disharmony could be minimized through the pressure and role of the current mayor. This is an effort from the organizational level to develop a universal language for setting priorities (for example using a qualitative scale to assess the condition of assets). In Bombana regency this disharmony is weakened only because some voices, especially accountants, prefer to be silent and submit it to two dominant discourses, BPKAD. However, it is evident that the presence of a silent voice and the beginning of the organization inherit a change in asset management.

\section{Discussion:-}

The Bombana regency executive statement is explicitly related to "best value", which in recent years has become mandatory for Bombana government, as the local government of the United Kingdom has also implemented it for a long time (Entwistle and Laffin, 2003; Ball, 2004; Enticott and Walker, 2005; Arnaboldi and Lapsley, 2008). Because the asset management position is under the umbrella of "best value", the government emphasizes it on performance management, a theme that is known because it appears in all policies.

In this case, the local government develops a comprehensive policy on asset management where accounting must play a central role. This makes the role of accounting accountants and humans bigger in asset policy, which has been suggested since the end of 2013. This development can be seen as an effort to position itself on the role of regional accountant authorities in the field of asset management, which is an attempt to claim central influence on organizations. management and management of city assets. In this case, accrual accounting in asset management and management has the capacity to explain the logic of government expenditure, which holds on public finance, with a more strategic view. However, the application of accrual accounting has become controversial and raises several problems, such as initial recognition of assets, asset categorization, and asset valuation (Deakin, 1999). However, the strategy of Bombana Regency is an important action because it strengthens the role of accountants and human accounting in asset management. Human accounting has been given a role in asset management, by defining ways to assess assets, which then rationalizes the planning and management of their assets.

Highlighting the potential for human accounting's contribution adds another element of complexity to policy, for example the presence of professional groups, consisting of all institutions with an interest in asset management. This provides a different perspective that is the focus of the discussion in this chapter in shaping the management of regional assets. The diversity of circumstances for various types of assets can lead to different discourses in establishing management policies, where not only internal voices are important, but also external actors, such as different users (eg, communities and commercial stakeholders), central government policies ( for example about social care and provision of education), and related professional bodies.

In this case, it appears in Bombana government, the advisory role for regional assets is carried out by the head of the regional finance and asset section. This section serves as a liaison in dialogue and discussion of public policies related to the management of regional assets and bridges differences in views between work unit managers for example. As part of the coaching role, they offer guidance to the city government about what is "best practice", especially regarding asset management issues. This section has formed an asset management group. This group has the responsibility to develop asset management policies, which are then offered to work units in the local government. This particular development highlights the existence of several voices with direct or indirect interests, in matters of regional asset management. The presence of a professional body in asset management policies explains that different actors, also different voices are given. 
Bombana is a regency with a diverse composition of assets, where stakeholders are involved in its use. Regent Bombana was given the responsibility to define asset management plans for Regional Development in 2013. This effort was intended to create a dominant voice (collective solidarity) in all parts.

The Head of the Regional Financial and Asset Management Agency (BPKAD) is the person who translated this unification business. The approach used in developing asset management policies is hierarchical. The approach introduces a new language, where the values and sustainability of the regional economy are the main ones. BPKAD describes their approach clearly, transparently and oriented towards creating value for the authorities and external stakeholders. However, the practice of asset management is still a mess, not yet fully integrated due to differences of views.

The desire to establish an asset rationality policy is strengthened by using a valuation method that is legitimized by the external to achieve Unqualified opinion. The definition of an asset management plan does not have to start from "the beginning", but it must be the data set they have, in a structured or maybe different format. Numbers, facts and technical measurements are considered central in asset management and they emphasize the progress made in assessing asset conditions in recent years.

Apart from the objectivity of the new data, due to lack of time in revising the database, the plan for the assets of Bombana Regency was designed initially based on traditional visual data. But the high desire to obtain Unqualified opinion, and they have used it to attract the attention of external auditors, who want to show that assets that are underestimated will cause serious problems and potentially cause permanent problems within the next five to ten years.

Bombana Regency acknowledges that planning priorities are ultimately decided by regional politicians, who are very careful when listening to voters. Durkheim reminds us that the problem of morality is fundamental to sociology as a scientific discipline. Morality, in Durkheim's view, has two aspects. First, Durkheim was convinced that morality is a social fact, in other words, morality can be learned empirically, is outside the individual, forces individuals, and can be explained by other social facts. This means that morality is not something that can be philosophized, but something we must learn as an empirical phenomenon. This is mainly because morality is closely related to social structure. Second, Durkheim was a sociologist of morality because his studies were driven by his concerns about the moral state of modern society. Much of Durkheim's sociology can be seen from his concerns regarding issues of morality. Supporting Durkheim, one of his colleagues wrote a review that "one will fail to understand the work that one does not take account of is the morality of their center and object" (Davy, translated in Hall, 1987: 5).

In the past BPKAD tried to prepare a complete program, which changed systematically, which made the BPKAD head limit their planning efforts for marginal work. This plan is structured on the basis of asset maintenance needs, regardless of the category of assets used, value, and asset depreciation. In this case, the voice of BPKAD is directly involved in asset planning through the preparation of asset expenditure and expenditure programs.

This system is intended to gather all voices, including politicians, to force their participation in a "rational" asset planning scheme. The priority system is the way they set autonomy and responsibility to the leadership, including in this case politicians. BPKAD's main task is proven not to the allocation in each of each work unit but to the overall resources, and by seeking new funding sources such as Public Private Partnership (PPP) for the sale of assets and additional loans. Although this practice involves assets managed by the agency, decisions about these matters are highly centralized and even financial reports reflect this. In addition, the valuation of their assets is driven by accounting related matters and the need to prepare a balance sheet, they do not even consider asset management as part of their scope, but are a coordinated scope.

Assets are considered not as physical entities, but as financial numbers, where the main task of accountants is to provide reliable financial reports. In doing this they have little to do with the managers of operational work units, but they have a close relationship with accountants in the operational work unit. In this case, evaluations made by the inspectorate for certain financial activities appear to be running smoothly. So here we have another voice in the context of seeking influence. The situation in Bombana Regency relating to asset management is one of several voices available. Therefore, there is no noisy voice, different interests and the lack of a unifying approach to the 
organization that makes Bombana a regency where we can see "the choir symphony to take action in the management of its original assets".

\section{Conclusion:-}

While social solidarity is very helpful in capturing the multi-layered structure of asset management, Durkheim's mechanistic solidarity helps in drawing the dynamics in which sound changes their position in the "orchestra", turning the "inaudible" into "audible", or even for sounds that dominant. In particular, the description above proves the benefits of: seeking strategic allies and carrying out fact-building.

By looking at Bombana Regency we have gotten a spectacle of how previously the voices were inaudible, increasing recognition at the national level through the BPK Audit. Despite the fact that managers in work units (dinas) are not part of certain categories of professionals, such as accountants, their situation has created work groupings, but synergized in social solidarity. This grouping can be relevant even though they are not based on a particular career background or identity. Furthermore, as suggested by Durkheim, they came from outside the traditional site (mechanistic), that it originated from a common interest which led to recognition on social networks.

\section{References:-}

1. Anderson, S.W., \& S.M. Young. (1999). The impact of contextual and process factors on the evaluation of activity-based costing systems. Accounting, Organizations and Society, 24, 525-559.

2. Arnaboldi, Michela, and Irvine Lapsley. 2008. "Making Management Auditable: The Implementation of Best Value in Local Government." Abacus. https://doi.org/10.1111/j.1467-6281.2007.00247.x.

3. Anthony, R.A. (1965). Planning and control system: a framework for analysis, Harvard University Press: Boston.

4. Ball, Amanda. 2004. “A Sustainability Accounting Project for the UK Local Government Sector?" Critical Perspectives on Accounting. https://doi.org/10.1016/S1045-2354(02)00209-5.

5. Enticott, Gareth, and Richard M. Walker. 2005. "Environmental Sustainability and Management Reform in Local Government: An Empirical Analysis.” Policy and Politics. https://doi.org/10.1332/0305573053870130.

6. Entwistle, Tom, and Martin Laffin. 2003. "The Multiple Strategies of the Local Government Association: Partner, Player and Think-Tank?” Policy and Politics. https://doi.org/10.1332/030557303321095798.

7. Milgrom, P., \& J. Roberts. (1992). Economics, organisation and management. Prentice-Hall International Englewood Cliffs.

8. Nicolaou, A.I., (2000). A contigency model of perceived effectiveness in accounting information systems: Organisational coordination and control effects. International Journal of Accounting Information Systems, 1, 91-105.

9. Zimmerman, J. (1997). Accounting for decision making and control, McGraw-Hill, Boston. 